\title{
A Validated Method for the Estimation of Casimersen Using RP-HPLC in Bulk and Pharmaceutical Dosage Form
}

\author{
Gowri Kusuma Kumari and Kantipudi Rambabu \\ Department of Chemistry, RVR \& JC College of Engineering, Chowdavaram, Guntur, Andhra Pradesh, India
}

\section{ABSTRACT}

New validated method for the estimation of Casimersen using RP-HPLC In Bulk and Pharmaceutical Dosage form. Chromatographic separation was achieved on a Waters Phenyl Hexyl column (150x4.6mm, $3.5 \mu)$ using isocratic elution with a mobile phase containing buffer and acetonitrile within the ratio of 50:50 as mobile phase with a flow of $1 \mathrm{ml} / \mathrm{min}$ at ambient temperature and UV detection was carried at $227 \mathrm{~nm}$. Analysis was achieved within 5 min over an honest linearity within the concentration range from $10-150 \mu \mathrm{g} / \mathrm{ml}$ of Casimersen. By injecting the standard six times, system suitability parameters were studied and the outcomes were well under the acceptance criteria. Precision and recovery study results were found to be within the suitable limit. By using the above technique assay of marketed formulation was performed and found to be within the limit. Degradation studies were carried out on Casimersen, with a purity threshold greater than purity angle in all conditions and within the acceptable range. The above mentioned technique was validated according to ICH guidelines

KEY WORDS: HPLC, CASIMERSEN, DEVELOPMENT, VALIDATION, DEGRADATION STUDIES.

\section{INTRODUCTION}

Casimersen, sold under the brand name Amondys 45 , is an antisense oligonucleotide medication used for the treatment of Duchenne muscular dystrophy (DMD) in people who have a confirmed mutation of the dystrophin gene that is amenable to exon 45 skipping . It is an antisense oligonucleotide of phosphorodiamidate morpholino oligomer (PMO). The most common side effects include upper respiratory tract infections, cough, fever, headache, joint pain and throat pain. Casimersen was approved for medical use in the United States in February 2021 and it is the first FDA-approved targeted treatment for people who have a confirmed mutation of the DMD gene that is amenable to skipping exon 45.

\section{MATERIAL AND METHODS / EXPERIMENTAL DETAILS}

Biosc Biotech Res Comm P-ISSN: 0974-6455 E-ISSN: 2321-4007

\section{crossef}

Identifiers and Pagination

Year: 2021 Vol: 14 No (9) Special Issue

Pages: 345-349

This is an open access article under Creative

Commons License Attribn 4.0 Intl (CC-BY).

DOI: $h t t p: / / d x . d o i . o r g / 10.21786 / b b r c / 14.9 .63$
2.1 Materials: Acetonitrile, Potassium dihyrogen ortho phosphate and ortho phosphoric acid, water (HPLC grade) were purchased from Merck (India) Ltd, Worli, Mumbai, India. All APIs of Casimersen as reference standards were procured from Glenmark Pharmaceuticals., Mumbai.

2.2 Tools: An HPLC system (Waters alliance e2695 model) consisting of quaternary pump, PDA detector-2998 was used. Data processing was performed with Empower 2.0 software.

2.3 Chromatographic Conditions:Chromatographic separation was carried out in isocratic mode at room temperature using Waters Phenyl Hexyl column (150x4.6 $\mathrm{mm}, 3.5 \mu$ ). A mixture of acetonitrile and buffer in 50:50 $\mathrm{v} / \mathrm{v}$ at a flow of $1 \mathrm{ml} / \mathrm{min}$ was used as mobile phase. The injection volume was $10 \mu \mathrm{l}$ and the run time was $5.0 \mathrm{~min}$.

2.4 Preparation Of Buffer: Take 1.36gm of Potassium dihyrogen ortho phosphate is dissolved in 1 lt of HPLC grade water adjust $\mathrm{pH}-2.5$ with OPA and filtered through $0.45 \mu$ filter paper.

\subsection{Diluent: Mobile phase was used as diluent.}

2.6 Preparation Of Standard And Quality Control Samples: Accurately weigh and transfer $100 \mathrm{mg}$ of Casimersen in $100 \mathrm{ml}$ volumetric flask and add app. $70 \mathrm{ml}$

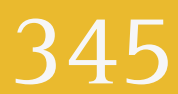


of diluent, sonicate to dissolve it for $30 \mathrm{~min}$. and made up to the mark with diluent. Furthur dilute $5 \mathrm{ml}$ of the above solution to $50 \mathrm{ml}$ with diluents.

2.7 Preparation of Sample Solution: Accurately weigh and transfer weight equivalent to $100 \mathrm{mg}$ of Casimersen sample in $100 \mathrm{ml}$ of volumetric flask and add $70 \mathrm{ml}$ of diluent. Sonicate to dissolve and dilute up to the mark with diluent. Take $5 \mathrm{ml}$ of the above solution and diluted to $50 \mathrm{ml}$ and filtered through $0.45 \mu$ nylon syringe filter. From literature survey there is no literature available in Casimersen till today. So that we take and developed new eco friendly method.

\subsection{Method Validation}

2.8.1 System Suitability: System suitability parameters were measured to verify the system performance. The parameters including USP plate count, USP tailing and \% of RSD are calculated and found to be within the limit.

2.8.2 Specificity: Specificity is the ability to assess unequivocally the analyte in the presence of other components, which may be expected to be present in the sample and standard solution. It was checked by examining the chromatograms of blank samples and samples spiked with Casimersen.

2.8.3 Accuracy: Accuracy is the closeness of the test results obtained by the method to the true value. It was assessed by the recovery studies at three different concentration levels. In each level a minimum of three injections were given and amount of the drug present, percentage recovery and related standard deviation were calculated.

2.8.4 Precision: Precision of the analytical method is the degree of agreement among individual test results. It was studied by analysis of multiple sampling of homogeneous sample. The precision of the present method was assessed in terms of repeatability, intraday and inter-day variations. It was checked by analyzing the samples at different time intervals of the same day as well as on different days.

2.8.5 Linearity: Linearity of an analytical method is its ability to obtain results directly proportional to the concentration of the analyte in the sample within a definite range. The six series of standard solutions were selected for assessing linearity range. The calibration curve was plotted using peak area versus concentration of the standard solution and the regression equations were calculated. The least squares method was used to calculate the slope, intercept and correlation coefficient.

2.8.6 Stress Degradation: Stress degradation should be no interference between the peaks obtained for the chromatogram of forced degradation preparations. Stress degradation studies were performed as per ICH guidelines Q1 (A) R2. The degradation peaks should be well separated from each other and the resolution between the peaks should be at least 1.0 and the peak purity of the principle peaks shall pass. Forced degradation studies were performed by different types of stress conditions to obtain the degradation of about $20 \%$.

2.8.7 Robustness: Robustness of an analytical procedure is a measure of its ability to remain unaffected by small but deliberate variations in method parameters and provides an indication of its reliability during normal usage. Robustness study was performed by injecting standard solution into the HPLC system and altered chromatographic conditions such as flow rate $( \pm 0.2 \mathrm{ml} /$ min), organic content in the mobile phase $( \pm 10 \%)$. The separation factor, retention time and peak asymmetry were calculated by determining the effect of the modified parameters.

\section{RESULTS AND DISCUSSION}

The current study was designed to develop a simple, precise and rapid analytical RP-HPLC method, which can be used for the analysis of assay method for he estimation of Casimersen in bulk and pharmaceutical dosage form. The chromatographic conditions were optimized in order to provide a good performance of the assay. To optimize mobile phase, various combinations were tried for Casimersen. The final working mobile phase is buffer and acetonitrile in the composition of 50:50 v/v. Mobile phase for drug was selected based on its polarity. Detection was carried out in several wavelengths in order to obtain enough sensitivity for the two APIs in smaller proportion (Casimersen). At last the wave length $227 \mathrm{~nm}$ was selected showes good absorbance. The flow rate was $1.0 \mathrm{ml} / \mathrm{min}$. The retention time for Casimersen were 3.251 min respectively. The proposed method is validated in accordance with the ICH guidelines with all of the results within the limits. The detection was carried out with a total runtime of 10.0 min. Optimized chromatographic conditions were shown in table 1.

Table 1. Optimized chromatographic conditions

\begin{tabular}{|l|c|}
\hline Parameter & Condition \\
\hline Stationary phase & $\begin{array}{c}\text { Waters Phenyl Hexyl } \\
(150 \times 4.6 \mathrm{~mm}, 3.5 \mu)\end{array}$ \\
\hline Mobile phase & $\begin{array}{c}\text { Buffer: Acetonitrile } \\
(50: 50, \mathrm{v} / \mathrm{v})\end{array}$ \\
\hline Injection volume & $10 \mu \mathrm{ml}$ \\
\hline Flow rate & $1.0 \mathrm{~min}$ \\
\hline Column temperature & Ambient \\
\hline Wave length & $227 \mathrm{~nm}$ \\
\hline Run time & $5.0 \mathrm{~min}$ \\
\hline Retention time of Casimersen & $3.251 \mathrm{~min}$ \\
\hline$*$ nm: Nanometer & \\
\hline
\end{tabular}

System Suitability: The system suitability was performed by injecting standard solution containing $100 \mu \mathrm{g} / \mathrm{ml}$ of Casimersen in six replicates. The results indicate that the system suitability parameter is within the limit. System 
suitability results were shown in table 2 and the standard chromatogram was shown in figure 1.

Table 2. Results of system suitability

\begin{tabular}{|l|c|}
\hline Parameter & Casimersen \\
\hline Theoretical plate count & 8762 \\
\hline Tailing factor & 0.84 \\
\hline Resolution & - \\
\hline Retention time & 3.252 \\
\hline
\end{tabular}

Figure 1: Chromatogram of system suitability

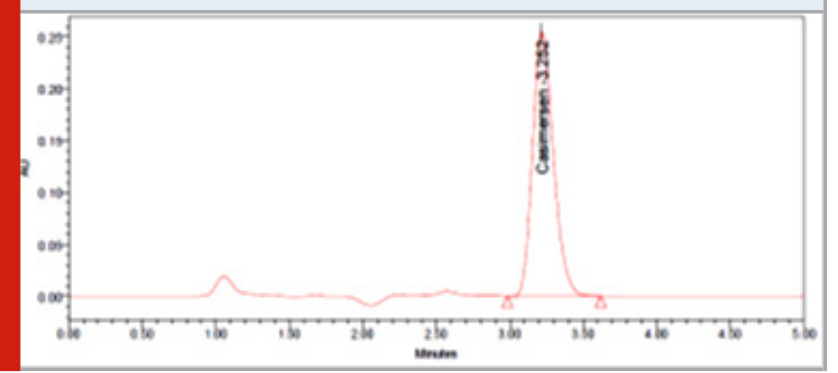

Specificity: There was no interference from blank at the retention time of Casimersen. Figure 2 represents the blank chromatogram.

Figure 2: Chromatogram of blank

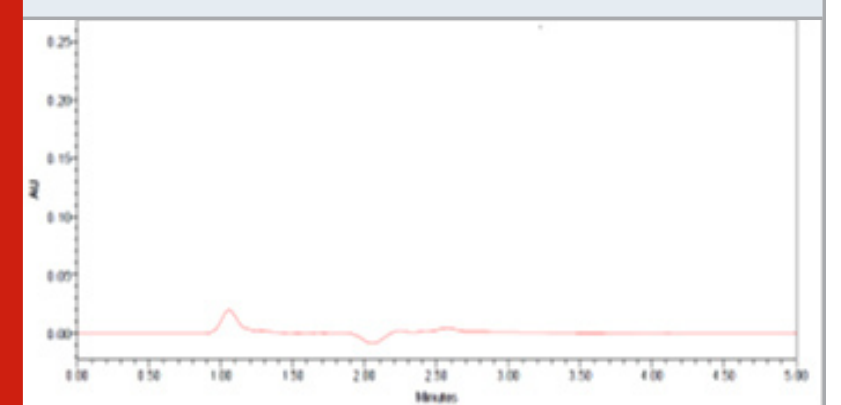

Table 3. Results of linearity

\begin{tabular}{|l|c|c|}
\hline \multirow{2}{*}{ S. No } & Casimersen & \\
\cline { 2 - 3 } & Concentration $(\mu \mathrm{g} / \mathrm{ml})$ & Area \\
\hline \multirow{2}{*}{1} & 10.00 & 259986 \\
\hline 2 & 25.00 & 649966 \\
\hline 3 & 50.00 & 1299932 \\
\hline 4 & 100.00 & 2599863 \\
\hline 5 & 125.00 & 3249829 \\
\hline 6 & 150.00 & 3799856 \\
\hline
\end{tabular}

Linearity: Linearity was determined by plotting a calibration curve of peak area against their respective concentration. From this calibration curve it was found that the curve was linear in the range of $10-150 \mu \mathrm{g} / \mathrm{ml}$ of Casimersen. The regression equations for calibration curve of Casimersen was $Y=25599 x+11930\left(R^{2}-0.9998\right)$, the results were shown in table 2 and the calibration plots were shown in figure 5 .

Figure 3: Calibration plots of Casimersen

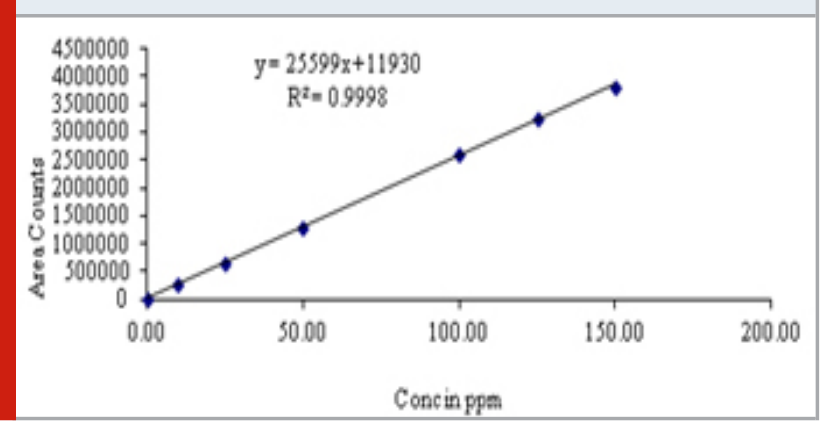

Table 4. Results of method precision \&t Intermediate precision

\begin{tabular}{|l|c|c|}
\multirow{2}{*}{ S. No. } & Area of & Area of Intermediate \\
\cline { 2 - 3 } & method precision & precision \\
\hline 1 & 2545634 & 2566789 \\
\hline 2 & 2555741 & 2577465 \\
\hline 3 & 2563782 & 2556644 \\
\hline 4 & 2555578 & 2598886 \\
\hline 5 & 2557783 & 2568893 \\
\hline 6 & 2544788 & 2588937 \\
\hline Mean & 2553884 & 2576269 \\
\hline Std. dev & 7352.42 & 15510.34 \\
\hline \% RSD & 0.28 & 0.60 \\
\hline
\end{tabular}

Table 5. Results of accuracy

\begin{tabular}{|l|c|c|}
\hline Accuracy & $\begin{array}{c}\text { Amount of } \\
\text { Casimersen }\end{array}$ & \% Recovery \\
\hline 50 & 50 & 100.04 \\
\hline 100 & 100 & 100.21 \\
\hline 150 & 150 & 99.98 \\
\hline
\end{tabular}

Table 6. Results of robustness

\begin{tabular}{|l|c|}
\hline Parameter & \% RSD of Casimersen \\
\hline Flow $(0.8 \mathrm{ml} / \mathrm{min})$ & 0.45 \\
\hline Flow $(1.2 \mathrm{ml} / \mathrm{min})$ & 0.72 \\
\hline Organic phase $(55: 45)$ & 1.01 \\
\hline Organic phase (45:55) & 0.58 \\
\hline
\end{tabular}

Precision: Precision of this method was assessed in terms of intraday (repeatability) and (intermediate precision) variations. The intraday studies were determined by performing six repeated analysis of the sample solution of Casimersen on the same day under the same 
experimental conditions. The intermediate precision of the method was carried out in the same laboratory by studying the analysis with different analyst and different instrument. The method is highly precise as \%RSD values were found to be $<2 \%$. Good recoveries of the drug were obtained at each added concentration, indicating that the method was accurate. Table 4 gives the method precision and intermediate precision.

Table 7. Results of forced degradation

\begin{tabular}{|l|c|}
\hline Stress parameter & $\begin{array}{c}\text { \% of degradation } \\
\text { Casimersen }\end{array}$ \\
\hline $\begin{array}{l}\text { Acid degradation } \\
\text { (1N HCl+ reflux+ 24 hrs) }\end{array}$ & 15.5 \\
\hline $\begin{array}{l}\text { Alkali degradation } \\
\text { (1N NaOH+ reflux+ 24 hrs) }\end{array}$ & 12.8 \\
\hline $\begin{array}{l}\text { Peroxide degradation } \\
\text { (30\% Peroxide+ reflux+ 24 hrs) }\end{array}$ & 11.6 \\
\hline $\begin{array}{l}\text { Photo degradation (UV light } \\
(200 \mathrm{~W} \text { h/m2) and fluorescent } \\
\text { light (1.2 million lux-hrs) }\end{array}$ & 14.3 \\
\hline * nm: Nanometer & \\
\hline
\end{tabular}

Figure 4: Chromatogram of acid degradation

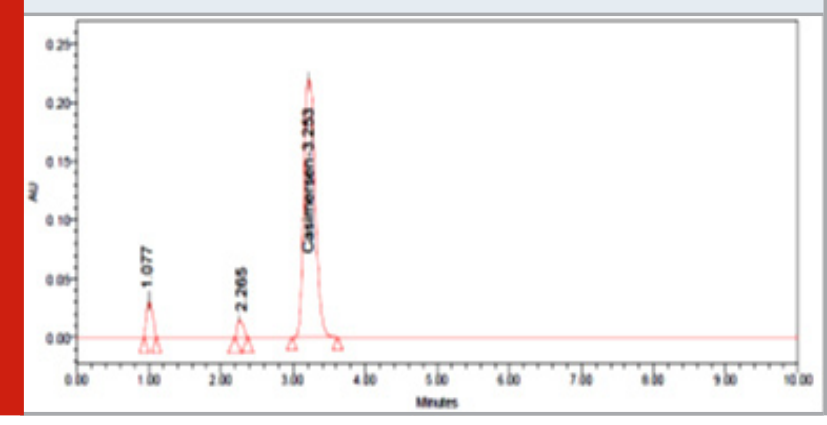

Figure 5: Chromatogram of alkali degradation

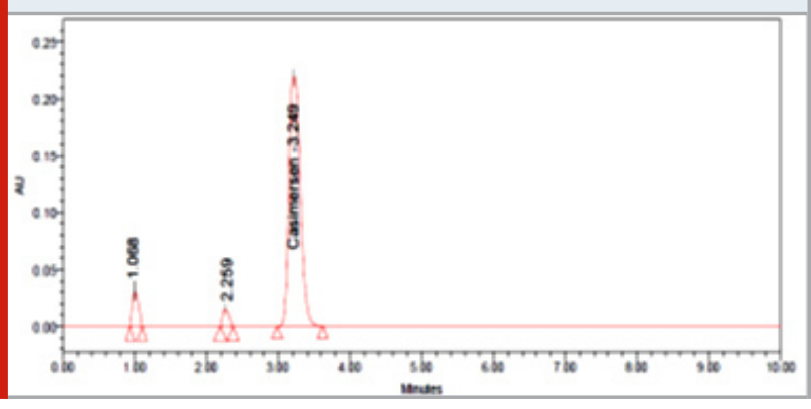

Accuracy: The accuracy of the method was performed by calculating the recovery experiments at three levels (50\%, 100\% and 150\%). APIs with concentration 50, $100,150 \mu \mathrm{g} / \mathrm{ml}$ of Casimersen were prepared. The test solution was injected three times for each spike level and assay was performed as per the test method. The recovery results were close to $100 \%$ and also the RSD values were less than $\pm 2 \%$. The percentage recovery, mean and relative standard deviation were calculated.
Figure 6: Chromatogram of peroxide degradation

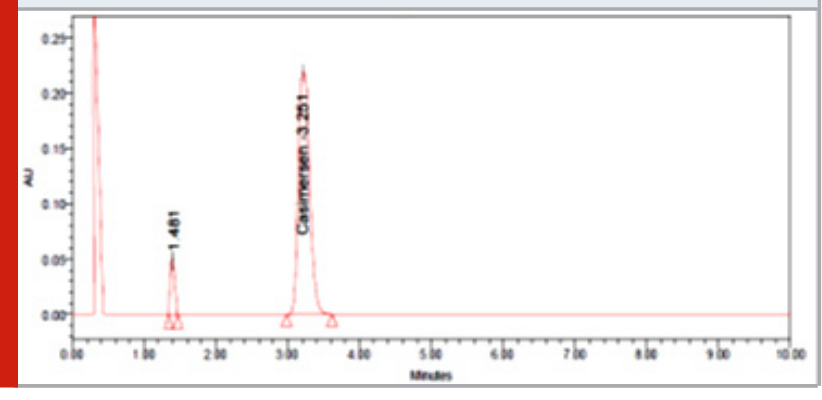

Figure 7: Chromatogram of photo degradation

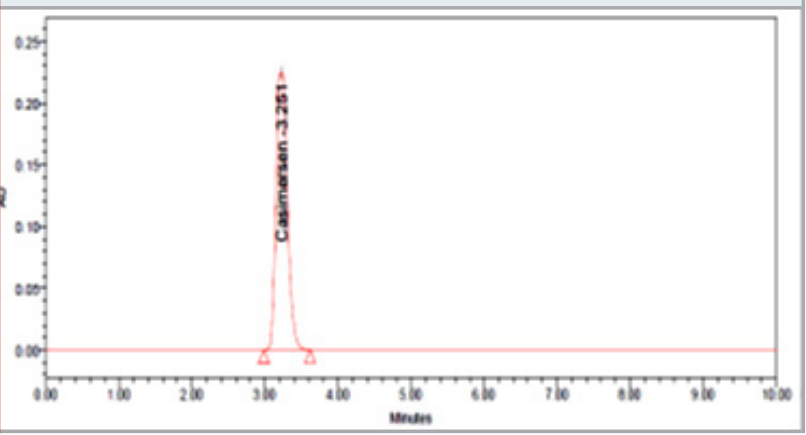

Recovery values demonstrated that the method was accurate within desired range. Accuracy results were shown in table 5 .

Robustness: Robustness of the chromatographic method was determined by varying flow rate and mobile phase composition. \% RSD was found to be within the acceptable limit. Robustness results were shown in table 6.

Forced Degradation: The proposed method can be used for release and stability studies for effective evaluations and can be considered as stability indicating method. The forced degradation study was carried out according to the ICH requirements include acid, base, oxidation, photo degradation. From the chromatograms it is evident that the selected drugs were stable under the applied stress conditions though the degraded peaks were observed. Forced degradation study results were shown in table 7 and the degradation chromatograms were shown in figure 5, 6, 7 and 8 respectively. However, the study of forced degradation had never been done or published in any journal, it was the first stabilising LC technique for Casimersen quality control. The devised approach was validated in accordance with ICH requirements and found to be very precise, quick, simple, cost-effective, and sensitive to the specific pharmaceutical dosage form.

\section{ACKNOWLEDGEMENTS}

I thankful to my guide for encouragement and supporting to finish this research work.

Competing Interests: There is no competing of interests 
Authors' Contributions: Autor 1 designed the study, performed the statistical analysis, wrote the protocol, and wrote the manuscript. Autor 2 to check the work and review the manuscript.

\section{REFERENCES}

Beksac MS, Tanacan A, Aydin Hakli D, Orgul G, Soyak B, Balci Hayta B, Dincer P, Topalo®lu H . Gestational Outcomes of Pregnant Women Who Have Had Invasive Prenatal Testing for the Prenatal Diagnosis of Duchenne Muscular Dystrophy. Journal of Pregnancy. 2018; $1-5$.

Crooke ST . Molecular Mechanisms of Antisense Oligonucleotides. Nucleic Acid Therapeutics. 2017;27 (2): 70-77.

Dias N, Stein CA. Antisense oligonucleotides basic concepts and mechanisms. Molecular Cancer Therapeutics. 2002;1 (5): 347-55.

FDA Approves Trageted Treatment for rare Duchenne Muscular Dystrophy Mutation. U.S. Food and Drug Administration (FDA). Retrieved February 25, 2021. https://www.fda.gov/news-events/pressannouncements/fda-approves-targeted-treatmentrare-duchenne-muscular-dystrophy-mutation-0.

Ibrahim B. HPLC-UV method for quantification of favipiravir in pharmaceutical formulations. Acta Chromatographica. 2021:33(3):209-215.

Jeremy P. T. Ward; Jane Ward; Charles M. Wiener. The respiratory system at a glance. Wiley-Blackwell. 2006;11.

Qato DM, Wilder J, Schumm L, Gillet V, Alexander $\mathrm{G}$. Changes in prescription and over-the-counter medication and dietary supplement use among older adults in the united states, 2005 vs 2011. JAMA Internal Medicine. 2016;176 (4): 473-482.

Rambabu K, Narayana Murty N N V V S S , Ramasrinivas, Rao N G. Stability indicating method development and validation for the determination of bilastine and its impurities by UPLC method. IJPSR. 2020; 11(3): 13121321.

Rodrigues M, Yokota T. An Overview of Recent Advances and Clinical Applications of Exon Skipping and Splice Modulation for Muscular Dystrophy and Various Genetic Diseases. Exon Skipping and Inclusion Therapies. Methods in Molecular Biology. 2018;1828:31-55.

Sully EK, Geller BL, Li L, Moody CM, Bailey SM, Moore AL, Wong M, Nordmann P, Daly SM, Sturge CR, Greenberg DE. Peptide-conjugated phosphorodiamidate morpholino oligomer (PPMO) restores carbapenem susceptibility to NDM-1-positive pathogens in vitro and in vivo. The Journal of Antimicrobial Chemotherapy. 2017;72(3):782-790.

Sanagapati M, Dhanalakshmi K, Nagarjuna Reddy G, Sreenivasa S. Method Development and Validation of Dapagliflozin in API by RP-HPLC and UV Spectroscopy. International Journal of Pharmaceutical Sciences and Drug Research 2014;6(3): 250-252.

Tennyson CN, Klamut HJ, Worton RG. The human dystrophin gene requires 16 hours to be transcribed and is cotranscriptionally spliced. Nature Genetics. 1995;9(2):184-90.

Thomas M, Del Mar C, Glasziou P. How effective are treatments other than antibiotics for acute sore throat. Br J Gen Pract. 2000;50(459):817-20. 